\title{
Mobile TV in Everyday Life Contexts - Individual Entertainment or Shared Experiences?
}

\author{
Virpi Oksman ${ }^{1, *}$, Elina Noppari ${ }^{2}$, Antti Tammela ${ }^{1}$, \\ Maarit Mäkinen ${ }^{2}$, and Ville Ollikainen ${ }^{3}$ \\ ${ }^{1}$ VTT Technical Research Centre of Finland, Sinitaival 6, Tampere, Finland \\ ${ }^{2}$ University of Tampere, Tampere, Finland \\ ${ }^{3}$ VTT, Espoo, Finland \\ virpi.oksman@vtt.fi
}

\begin{abstract}
TV has often been regarded primarily as a traditional family medium [8], because it is mainly watched at home and used as a basis for interaction with others. Now that the mobile phone, which people seem to experience as a personal communication device, has developed functionalities peculiar to mass media, including a TV feature, it is interesting to know how these functionalities will be used throughout the day and in different everyday life contexts. Will mobile TV used mostly on the go or as an additional media at home? Will it become as a highly individualized media format or will the watching experience typically be shared with others?

This paper examines the users' mobile TV choices in different everyday life contexts. The data is based on ongoing empirical research in Finland in 2006. The tested mobile TV services included both news and entertainment contents, and were tested in $3 \mathrm{G}$ and DVB-H networks.
\end{abstract}

Keywords: Mobile TV, mobile news, mobile media, use contexts, user experiences.

\section{Introduction}

Being able to view news and other media contents such as your favourite soap operas on the go on a wireless handset has a value in many situations. On public transportation a mobile TV service offers a way to keep up-to-date all the time. The same goes for other public spaces like coffee shops, shopping malls, bus stops, entrance halls, queues in supermarkets and waiting rooms. Also in private spaces, there is a need for mobile media. Even in your own living rooms, at work, at a summer house, in a taxi or a private car, the opportunity to use mobile TV is interesting. Some family members may even wish to have their own personal mobile media service at home [13]. However, it is not yet clear, in which extent people will value the functional blending of mobile telephony and mass media broadcasting and how valuable the mobile TV service would be for users [9]. Therefore, it is important to find out in what kind of situations and for what purposes people would like to use

\footnotetext{
* Corresponding author.
} 
mobile TV. On balance, we will next take a closer look on some earlier findings of mobile TV user studies.

\subsection{Some Earlier Experiences on Mobile TV Use Contexts}

The usage of mobile phones evolves in the three general user spheres of home, work and public. Quite typically, mobile phones are regarded as devices for use in the public sphere for example while waiting or commuting. They are used kill dead moments and to keep their users entertained or up-to-date.

Whereas the public sphere is going to remain an important area for mobile television usage, some studies have shown that mobile services are measurably used in the private area. For example mobile television pilot in Oxford, UK, revealed that about 50 percent of the test users viewed mobile television at home and didn't move anywhere while viewing. Typical time for using mobile television was late night, in bed, just before one was falling asleep. [1]

According to a Finnish mobile television pilot, people use different content types in different locations. News and information services are used everywhere throughout the day, and the mobile phone is considered as a valuable channel especially when something newsworthy suddenly happens. Live broadcasts of sports are watched anywhere if there is no conventional TV available. Series and entertainment services are viewed in short periods during waiting periods, for example on public transportation. Music is also listened to when on a move. Films and longer programs are only watched when the conventional TV is not available. Users may start watching a movie via the mobile phone and continue watching on their main TV when they get home. Mobile TV is often viewed during the daytime, which differs from the peak viewing times viewing of traditional television. [9]

The use of mobiles in the public sphere has certain limitations. For example users have been worried about becoming absorbed in mobile multimedia content, which requires their visual attention. They fear increased risks of accidents and lapses. The possibility of listening to music or the radio while on the move is thus highly valued, because it doesn't need visual attention. Also text legibility may be difficult when on a move. [5]

\subsection{From News to User Generated Contents}

The findings of a number of studies made on mobile TV show that the most popular content is news. [13, 6, 9] Different mobile television content types listed by their popularity are: 1 . news 2 . music 3 . sports 4 . cartoons 5 . movies 6 . soap operas 7 . sitcoms. [6]

News is well suited to mobile phones, because the use of mobile TV bursts often lasts less than 10 minutes $^{2}$. News channels are also quite easily re-broadcasted over

${ }^{1}$ According to a Finnish mobile television pilot, $43 \%$ of test users used mobile television for killing time and $40 \%$ to stay up-to-date while on a move.

${ }^{2}$ In a Finnish mobile television pilot an average use time of mobile television was 5-20 minutes daily. Only very active users viewed mobile television more than that - up to maximum 40 minutes per day. 
the mobile phone, because the content of the channel is continually news: if the user selects the mobile news channel (s)he is most likely to get what (s)he expected. Other channels may have to think how well their broadcasting is fitting to the mobile environment. For example, if a mobile TV user selects a music channel, it's disappointing if there isn't music in the agenda during her/his short period of viewing. The limited time of mobile television use has ramifications for both on the type of content and the way that people consume it. [13, 4, 9] Most likely, customized services which address specific interests of the individual user will probably become more important. [3]

Digital music is one of the most popular form of mobile entertainment and it is supposed to be a key driver for customer adoption of new $3 \mathrm{G}$ services. The market for music-capable phones is expected to grow quickly. [7] According to a Siemens survey, the most attractive applications for American consumers are mobile email, mobile music and mobile TV. [12]

User generated podcasting - audio and video file sharing to a portable device - is also a significant phenomenon and regarded as one of the most important content types for mobile TV. There are plenty of amateur podcasters all over the world, which is seen for example in the enormous success of Youtube. There are sites for podsafemusic ${ }^{3}$, where podcasters are able to download free background music for their shows. Other services are also created for podcasters, like podcast editing and voice offering services. The whole podcasting or mobcasting ${ }^{4}$ phenomenon may affect the forms of present media supply. For example the Finnish Broadcasting Company, YLE, which started its podcasting experiment in autumn 2005, has recounted that one of the most wished-for podcast contents is a radio play. ${ }^{5}$ The popularity of podcasting certainly challenges traditional media and their business models. The first open source radio station, based on podcasting, started in April 2005, in San Francisco. ${ }^{6}$ The channel is moderated and quality controlled for unacceptable material. Overall, usergenerated contents multiplies the whole media supply, and users have countless of channels to get contents just to their likings.

Clearly, user choices and preferences will determine the success of mobile TV services. Indeed, for media companies and consumers, mobile media is nothing new. Print media such as newspapers or magazines are mobile; the same holds true for media such as the car radio, or Walkman. [2] Thus, if new mobile broadcast services are to be successful, questions regarding the relevance of the service to consumers need to be asked. The research needs to ask questions such as: How does the service improve users' lives or help them? Why it is valuable to them? It is also important to consider the issues of when and where the usage will take place, as the mobile broadcasting services will most likely to be used in different locations and times than the fixed media and information technologies. [10] Taking all the above points into consideration, the paper will next present the findings of a user study.

\footnotetext{
${ }^{3}$ http://music.podshow.com

${ }^{4}$ mobcasting is podcasting to a mobile phone.

${ }^{5} \mathrm{http}: / /$ blogit.yle.fi/podcasting

${ }^{6}$ www.kyoradio.com
} 


\subsection{Research Questions}

To find out how people would like to use mobile TV services, this article focuses on three main research themes based on empirical research:

- In what kind of contexts and situations people would like to use mobile TV? Is it used as an individualized media device or in social situations, in fixed locations or mainly when the user on the move?

- When is the mobile prime time? Is it the same as television prime time, or perhaps a little bit earlier?

- What kind of contents people would choose to watch on mobile TV?

\section{Research Methods}

The focus of our research is on developing mobile TV technologies and usability of the services. With our methodological approach, we hope to gain new insights into users' requirements and expectations of mobile television.

The purpose of the first field study was to explore users' media choices in different situations. The tested media service prototype combined text, audio and video and included solely news contents. Qualitative and quantitative methods are combined to make sure that adequate data is collected. Semi-structured interviews and media diaries help us understand users' media habits and how they voice their expectations and preferences. Log data reveals the time and duration of actual occurrences of service use. We asked the users to take some photos with the camera phone about the situations in which they used the mobile news service, and of other places, things or contexts that are important to them. This helps us gain an understanding about the role of media in the users' everyday lives.

The first field test started in March 2006 with users who used the service with 3G phones (Nokia 6630 and N70) for one month with Elisa subscription. Before the test period, the users were interviewed and they received information concerning the test. Demographic data and media user profiles were gathered from the users. The ages of the users ranged from 23 to 56. All of them worked at least part time. During the test period, the informants reported their user experiences in a test diary. After the test, the users were asked to fill in a usability evaluation form and they were interviewed again. The usability form covered questions such as the navigation and the ease with which the different functions could be utilized. The testers were also asked to assess how enjoyable they found watching the news and other media on the screen of the mobile phone. The log data of the service use was collected and analyzed statistically. The similar kinds of methods were used in the second field test, which started in October 2006 and ended in December; with the exception that the log data was not possible to collect from these applications. The main aims of the second test were to examine the user choices when different, more varied media contents were available and to estimate the quality difference between $3 \mathrm{G}$ TV and DVB-H TV as well as the usability of the services. Ten families tested 3G TV and DVB-H TV with Nokia N92 for a period of one month. The tested mobile TV services consisted of a wide range of 
different kinds of contents: from all the main TV channels to sports, news channels and from fashion TV to user generated contents.

The both of the test groups consisted of persons who have been using mobile phones and mobile services actively during the last few years. They were also keen news and media followers but had different kind of media user profiles each. Some of them were very loyal newspaper readers, while others regarded the Internet or TV as the best news or entertainment source. The test users had different kinds of hobbies, lifestyles and interests. During the test, they carried the test phone as their primary mobile, using it for both professional and personal communication. They did not have pay for using the developed services. Of course, the price of using the mobile TV services, when they are finally finished products on the market, is also a significant factor that will affect the use. Naturally, creating good technology and services and profitable business models are all difficult activities and if mobile broadcasting services are to become successful commercial activities, companies offering services have to devote significant attention to consumers and the market. [10, 3]

\section{The Contexts of Use}

- What I appreciated most was the mobility of the service. Situations where you're travelling from one place to another and you have some time to spare; it's perfect for that. I watched a lot of news. I usually don't have much time for TV. (Woman, 34)

The test users reported on their diaries about their media habits, expectations and preferences. It appeared that they valued greatly the possibility to watch mobile TV on the go. It was often used for just killing time but it obviously also possesses some novelty value which was present in the usage situations. It aroused curiosity also in situations with friends or colleagues. It was the most used media type in social situations when the device was tested with others.

- TV was the most interesting to me. The thing I used the most was TV news during my coffee break at work. That way I came to show my friends that I had a TV in my mobile. Some thought, well, you always have to have the most latest gadget. Others said, ok, that's interesting, but the screen is very small. The size of the screen caused a little doubt about whether or not it's worth it. (Man, 56)

The test users considered the service most useful while they are on the move and not at home or in situations where they are unattainable by regular media. However they used it also at home for mainly quick check ups and as a personal media device if they were not close to a TV-set. Users appreciated the ability to watch news any time they liked to.

It is very handy indeed that you are able to watch the news whenever it is suitable for you. You don't have to care about times. (Woman, 43)

The ability to select the media format suited for the situation at hand was considered important. Audio was perceived as suitable for situations where the user was mobile him/herself, e.g. while walking, cycling or roller skating. For situations 
when the user was sitting or standing still, the media form selected was more likely to be illustrated news, text or video.

"The media format (text, video, audio) has more significance when it associated with situations you find yourself in. If you need to know the contents of a specific item of news, then I'd opt for a moving image, kind of like news broadcasts on TV, that's condensed information. If you want a more in-depth view, you read from the paper or an electronic service." (Man, 42)

The use of the mobile TV raised discussion in the immediate circle of the testers. The general view was that its use was best suited to situations where other media were not available or where people found themselves with time on their hands. They could use the service while waiting for someone, during their break from work, or while travelling on public transportation. Users described it as a nice way of passing the time.

The mobile TV service was mainly used as an individualized, personal media format. However, while watching TV, the device became occasionally more social, but after the demonstration phase it was mostly used by one person only.

At work and where I study I would be with others, at home and in the bus I would use it on my own. It generated a lot of discussion about how it would work, what you could use it for and how nice it would be. For us mature students coming from different parts of Finland this would be really good as we tend to travel a lot from place to place. For when you're sitting on a train or in a bus or for lonely nights in student housing when you don't feel like going out. (Woman, 34)

Mobile TV was obviously not used while driving. Users mentioned that in noisy environments, like in a bus or in traffic, other media type than TV might be easier to use. The use of earpieces in a public place was seen as less awkward than it perhaps would have been before [see 11]; however, mobile TV would not be often used without earpieces for example in a bus, and sometimes it would be an extra effort to find and attach them to the phone.

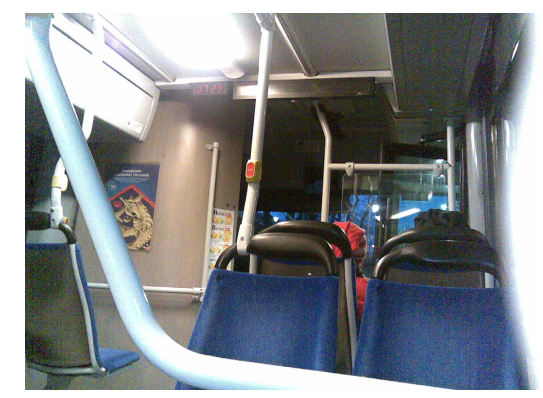

Fig. 1. The mobile prime place. The mobile TV was used often when moving from one place to another. 


\section{1 Mobile Primetime}

The average viewing time for mobile TV news video was relatively short, clearly under 5 minutes (a median for video duration was $1 \mathrm{~min} 43 \mathrm{sec}$ ). The mobile media service use spread relatively evenly for the whole day, although use was more frequent during the mornings (from 8 to 10) and before the noon (from 10 to 12) and early in the evenings (from 16 to 18 ).

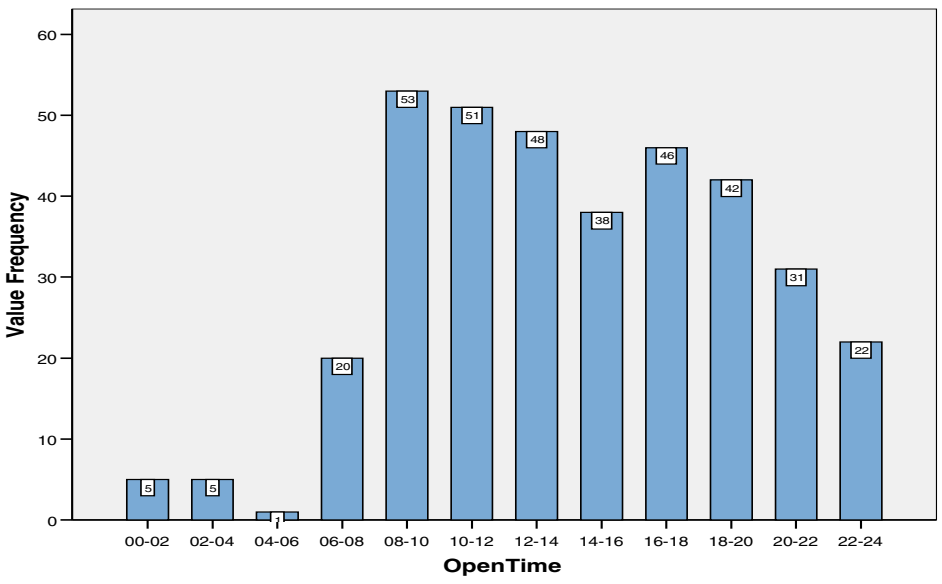

Fig. 2. The prime time of a mobile news service

The service use was most active in the beginning of the week. The usage tended to become less active during the weekends - it was remarkably low on Sundays, probably because people were at home watching regular TV broadcasts.

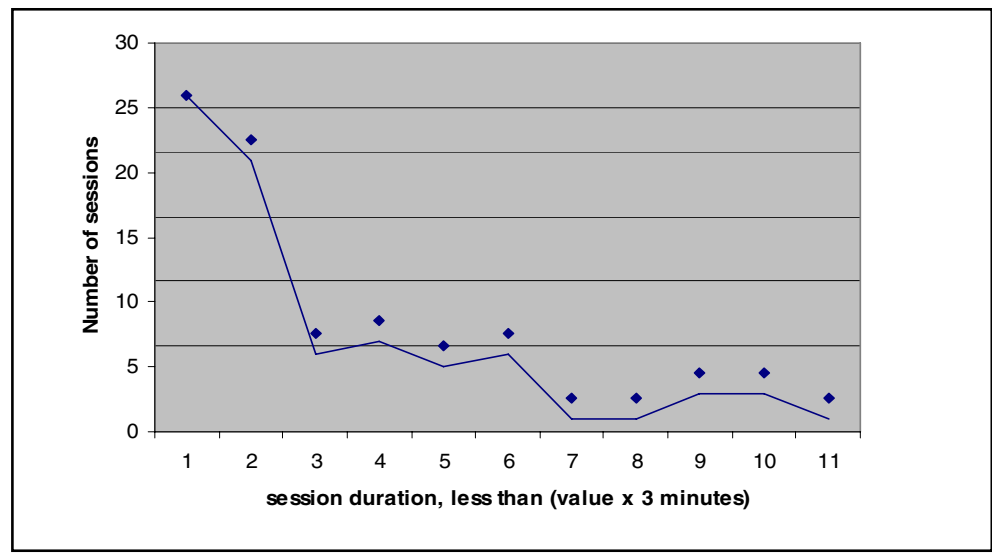

Fig. 3. The development of mobile TV sessions. It seems that the sessions tended to become shorter during the test. In this chart the first two testing days are ignored, as the usage activity tends to be especially high during the first couple of days. 


\subsection{The Most Interesting Media Contents in Mobiles}

Clearly, as the earlier studies show, news was considered as one of the most interesting media contents in mobiles. The categories of domestic $(25 \%)$, sports $(15 \%)$ and foreign news (9\%) attracted the most interest. Also the TV-program guide was checked quite often (11\%). The local news and children's sections were read more randomly. There was high demand only for the latest news - the older news from the archive were barely read at all.

Regarding the entertainment contents, mostly same contents were watched as on regular TV, but also special channels were liked for example a channel focusing on local cultural events. Thus familiarity was the most used criteria in choosing the TV channel. The test users mentioned the major Finish channels (MTV3, Nelonen and YLE) as the channels they watched most often.

Moreover the mobile TV changed their watching routines by offering the possibility to follow their favorite programs despite of their location. The time used for watching was also shorter than usual, and they could watch only the most essential or interesting parts of the programs.

I could not finish the movies until the end, but watched them about 15 to 20 minutes. I think I watched news more than usually. (Woman, 29)

Video watching durations were considerably longer than on the news field trial, approximately from 5 to 10 minutes (according the testers' own report) and also longer durations up till 20 to 40 minutes were reported. Besides the new contents, also $3 \mathrm{G}$ and DVB-H reception difference may have an influence on session durations.

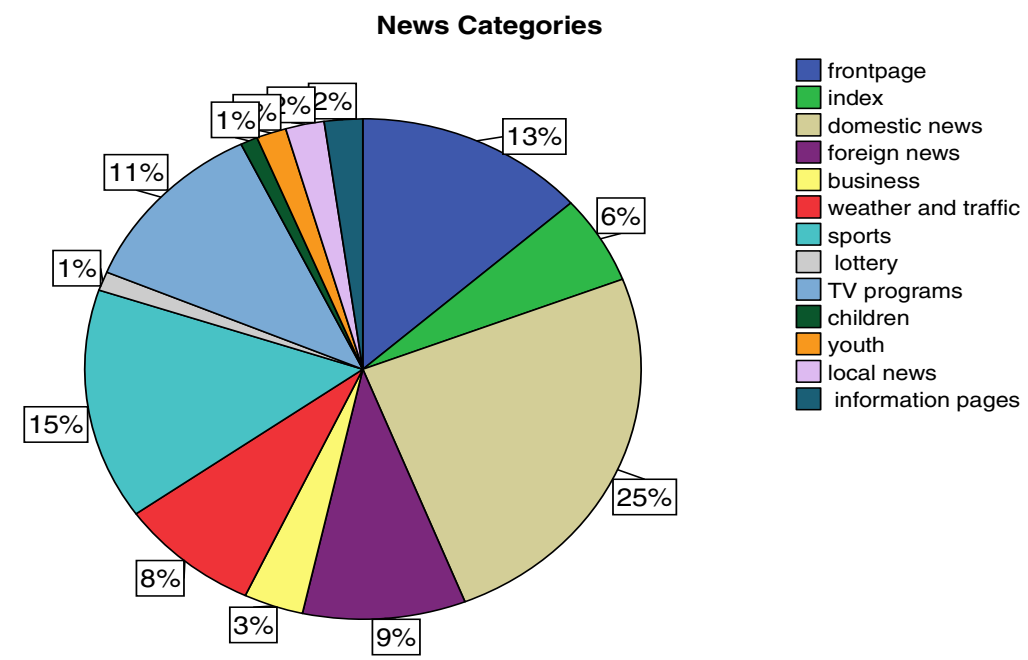

Fig. 4. The most popular news categories in mobiles. The regular news categories such as domestic news, sports and foreign news attracted the most interest in mobiles. 
Also certain reality TV series that the users want to keep up with real time were mentioned as interesting contents. During the test period an obvious example of this was the reality TV show Big Brother, which in addition to television, was followed also through other media. The most avid follower was a 27 -year old female student, who explained that it was essential daily to follow the events at the house from mobile TV while she was away from home.

The comments about interactive services of the mobile TV were most varying. Some users expected the mobile TV to include some kind of interactive services, while others didn't. The test users were mainly interested in applications for instance to buy or reserve concert tickets.

There could be interactivity in some channels, but too much of it would disturb. TV is for relaxing, and it requires some kind of passiveness. (Woman, 50)

The test users estimated that mobile TV would increase their media consuming from 5 to 10 percent or from 30 minutes to two hours per day. The extra time would include watching TV on the way to work, at the office, and in situations they don't have TV available.

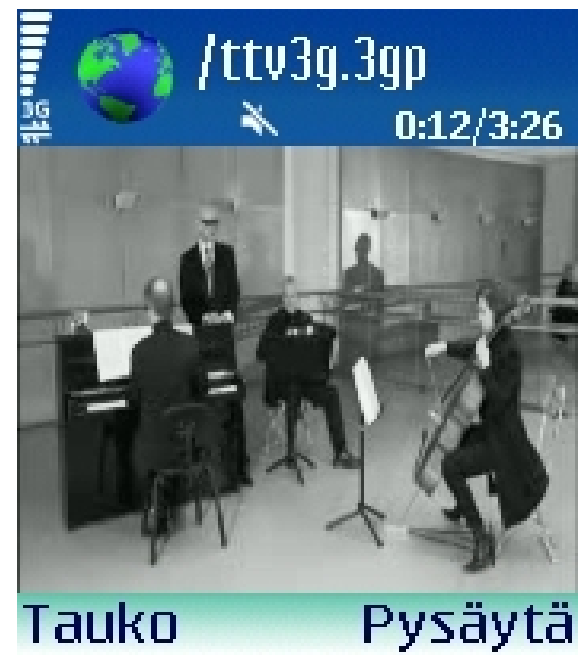

Fig. 5. New contents for mobile TV? On mobile TV, mostly the same entertainment contents were watched as on regular TV, but also new special channels were liked for example a channel focusing on local cultural events

\section{Conclusions}

Although the field tests were constructed around testing a service in its early stage with a quite small test group, they yielded certain interesting results on the uses of mobile TV services in different contexts of people's daily lives. The empirical research shows that a device optimised for voice and text communication can offer 
users an interesting visual experience such as fresh TV news and entertaining contents.

The mobile phone as media is suitable for many different situations. Mobility, diversity and real time effect are considered to be the most important characteristics of the service and that combination distinguishes the use of the news service from other media use. Users appreciated updated information and information-rich media forms for mobile news delivery as well as the ability to select the media format suited for the situation. There was high demand for the latest news in mobiles. Users also appreciated fast functions and easy usability.

The mobile TV service was mainly used as an individualized, personal media format. As personal communication devices are turning into multimedia communication devices delivering news and other mass media content, new questions about user experience challenges will emerge. Two users interestingly pointed out that they would expect the user interface to display a new functional or visual idea. They had recently started using a text-based syndicated news browser (Kanavat) that has its own "smooth" scroll implementation which they found pleasant. For these users, the new scrolling implementation signified the service providers' investment and commitment to developing a good service, and this increased the users' positive attitude towards the service.

Users appreciated condensed information and media forms for mobile TV and news delivery. Most users looked the headlines or followed news several times a day - much more often than the traditional TV and news prime times would allow. It would be interesting to find the causes behind this as well - do we crave for news because we fear catastrophes or is it just some kind of ritual?

Thus usability issues regarding the small screen user interfaces will be particularly important and the quality of reception is crucial. In the long run, it will also be crucial to discover what kind of existing and new media formats and distribution channels will best suit mobile media.

\section{References}

1. Dowell B. (2006) Viewing habits shift into the bedroom. http://technology.guardian.co.uk/print/0,,329451221-117802,00.htm

2. Feldmann, V. (2005) Leveraging Mobile Media: Cross-media Strategy and Innovation Policy for Mobile Media Communication. New York: Physica- Verlag.

3. Grobel, J. (2006) Mobile Mass Media: A New Age for Consumers, Business, and Society? In Groebel, J., Noel, E., Feldmann, V. (eds.) Mobile Media. Lawrence Erlbaum Publishers.

4. Knoche, H. \& McCarthy, J. D. (2004) Mobile Users' Needs and Expectations of Future Multimedia Services. Proceedings of WWRF12, 10-12 Nov 2004

5. Knoche, H. (2005) A User-centred Mobile Television Consumption Paradigm. Proceedings of Human Centred Technology Workshop, 28-29 June, Brighton, UK

6. Knoche, H., McCarthy, J. D. (2005) Good News for Mobile TV. Proceedings of WWRF14, 7-8 July 2005, San Diego, CA, USA.

7. May, H. \& Hearn, G. (2005) The Mobile Phone as Media. International Journal of Cultural Studies. Vol 8(2), pp. 195-211. 
8. McQuail, D. (1994) Mass Communication Theory. An Introduction. Third Edition. London:Sage.

9. Mäki, J. (2005) Finnish Mobile TV Pilot, Results. http://www.finnishmobiletv.com/press/Final_RI_Press_300805_english.pdf

10. Picard, R.G. (2005) Mobile Telephony and Broadcasting: Are They Compatible for Consumers. International Journal of Mobile Communications, Vo. 3.No. 1.

11. Repo, P., Hyvönen, K., Pantzar, M., Timonen, P. Mobiili Video (Mobile video). Helsinki: Kuluttajatutkimuskeskus, julkaisuja, 2003.

12. Siemens Communications Inc. (2006) Survey: US and World demand for wireless applications.

13. Södergard, C. (ed.) (2003) Mobile Television - Technology and User Experiences. Report on the Mobile-TV project. VTT Information technology. § 